\title{
Causes of damage and methods of repairing floor made on polystyrene concrete
}

\author{
Eukasz Drobiec ${ }^{1,{ }^{*}}$ and Pawel Piotrkowski ${ }^{2}$ \\ ${ }^{1}$ Department of Building Structures, Faculty of Civil and Environmental Engineering, Silesian \\ University of Technology, Akademicka 5, 44-100 Gliwice, Poland \\ ${ }^{2}$ Department of Building Structures, Faculty of Civil and Environmental Engineering, \\ Gdansk University of Technology, Narutowicza 11/12, 80-233 Gdansk, Poland
}

\begin{abstract}
The paper describes damages, tests and repair of the floor made on existing ceiling and expanded polystyrene concrete underlay. The floor was built on a reinforced concrete ceiling with an area of about $1050 \mathrm{~m}^{2}$. Significant damage in the form of cracks, detachments and unevenness was found in the floor. In order to determine the causes of damage, in situ tests and laboratory tests were carried out. It was found that the damage was caused by numerous performance errors. A test repair of the damage $(4.7 \times 6.0 \mathrm{~m})$ was carried out, and then the repair method was applied on the entire floor surface.
\end{abstract}

\section{Introduction}

The expanded polystyrene concrete (EPSC) is often used as a subfloor, a roof pitch layer $[1,2]$ or in fire retardant membranes in construction [3]. Some attempts were made to apply the EPSC for the production of precast wall elements [4]. The advantages of the EPS concrete include low weight (even 12 times smaller than ordinary concrete) and good thermal insulation. However, the EPSC exhibits increased shrinkage and significant creep as well as certain performance limitations [5-7]. The use of polystyrene concrete is in line with the global trend of environmental protection through recycling of used polystyrene elements $[1,4]$.

The paper describes damages, tests and methods of repairing the floor with a polystyrene concrete subfloor.

\section{Construction details}

The floor was built on existing reinforced concrete beam-and-slab ceiling (originally a roof). The area of about $1050 \mathrm{~m}^{2}$ was adapted to a new function (canteen). The adaptation required a superstructure and reconstruction of existing building, including reinforcement of several structural elements. The slab was strengthened by pouring a new, min. $5 \mathrm{~cm}$ thick layer of reinforced concrete over entire ceiling. Layer-to-layer interface was provided by using an adhesion layer and reinforcement pins. The existing $600 \times 600 \mathrm{~cm}$ grid of joists was

${ }^{*}$ Corresponding author: lukasz.drobiec@polsl.pl 
reinforced by increasing their height by $15 \mathrm{~cm}$ with an additional layer of reinforced concrete. The screed was made of a $9.5 \mathrm{~cm}$ thick layer of EPS concrete with a $1.5 \mathrm{~cm}$ thick selflevelling cement finish. It has been assumed that the reinforcement pins would be anchored in the EPSC layer or in layer below. The pins were inserted every $50 \mathrm{~cm}$, or $25 \mathrm{~cm}$ near the inverted beams. Floor expansion joints were planned along the column axis as parallel gaps along the sides of inverted beams. The beam system as well as location of reinforcement pins (dots on the plan) connecting the existing ceiling, top layer and EPS concrete are shown in Fig. 1. The cross-sections of reinforced slab and joist is shown in Fig. 2.

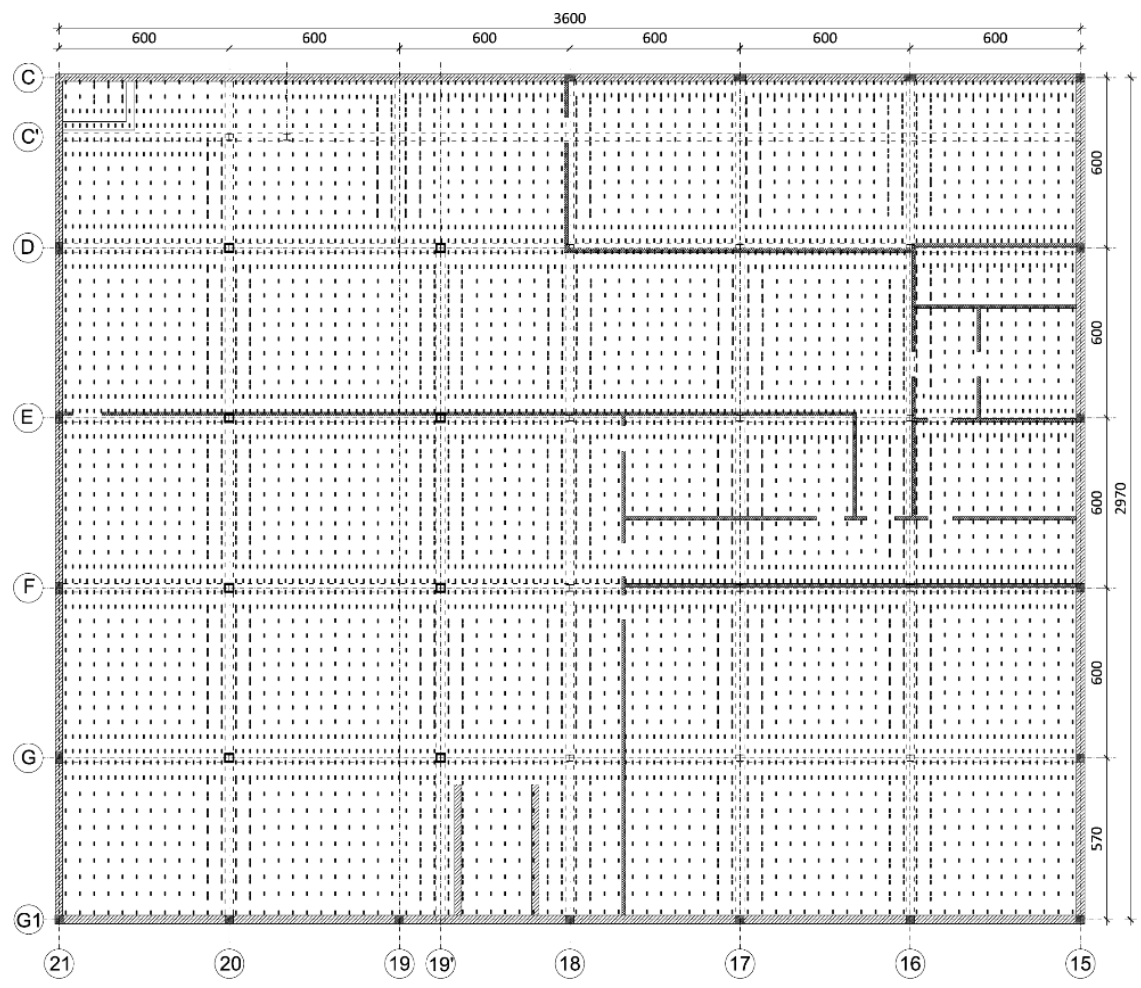

Fig. 1. Beam system and the location of reinforcement pins (connecting the existing ceiling, top layer and EPS concrete.

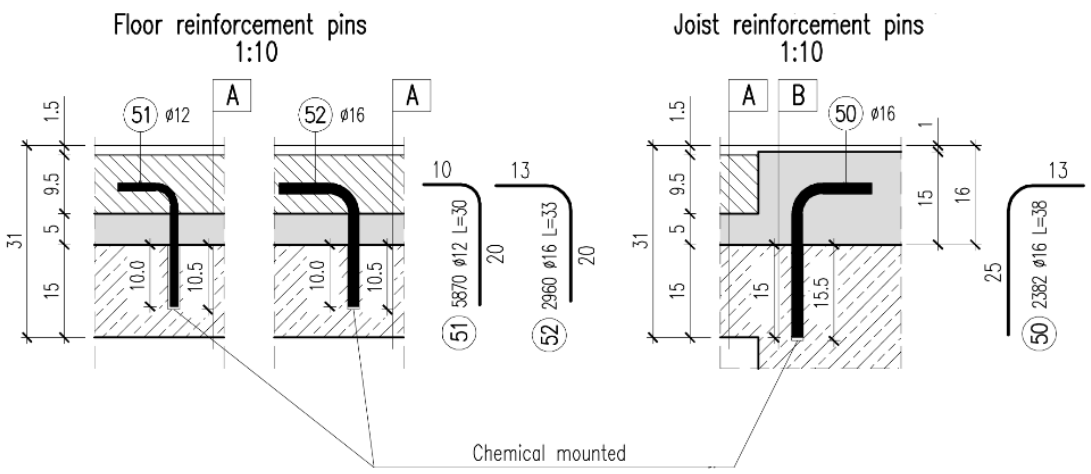

Fig. 2. Cross section of reinforced slab and reinforced joist. 


\section{Types of damage}

Already a few hours after the screed was made, numerous cracks have appeared on the surface. Additionally, top layer detachment as well as lack of homogeneity were observed. The crack width often exceeded $3 \mathrm{~mm}$. The cracks occurred both on surfaces of self-levelling screed over the EPS concrete layer and concrete poured over reinforced joists. Near the joists the cracks propagated down to the layer of the EPS concrete.

Visual inspection determined several performance errors, including uneven thickness of screed and EPSC, lack of precision in the execution of expansion joints and stratification of the concrete (up to three layers). The floor was clearly uneven - the slope of several slabs reached up to $16 \mathrm{~mm} / \mathrm{m}$, while spacing under two-metre-level and floor was up to $7 \mathrm{~mm}$. It was observed that floor cracks protruded beyond expansion joints, which proves that the cuts were made too late.

Attempts to repair the damages by injection were made, however, the holes were drilled vertically at a distance from the cracks, not as supposed through the cracks at a certain angle. The map of cracks, their width as well as floor slope are presented in Fig. 3. Chosen damages to the floor were shown in Fig. 4 and Fig. 5.

Entries in the construction log and weather archives for the day of EPSC and screed casting showed that the temperatures exceeded recommended by the manufacturers values.

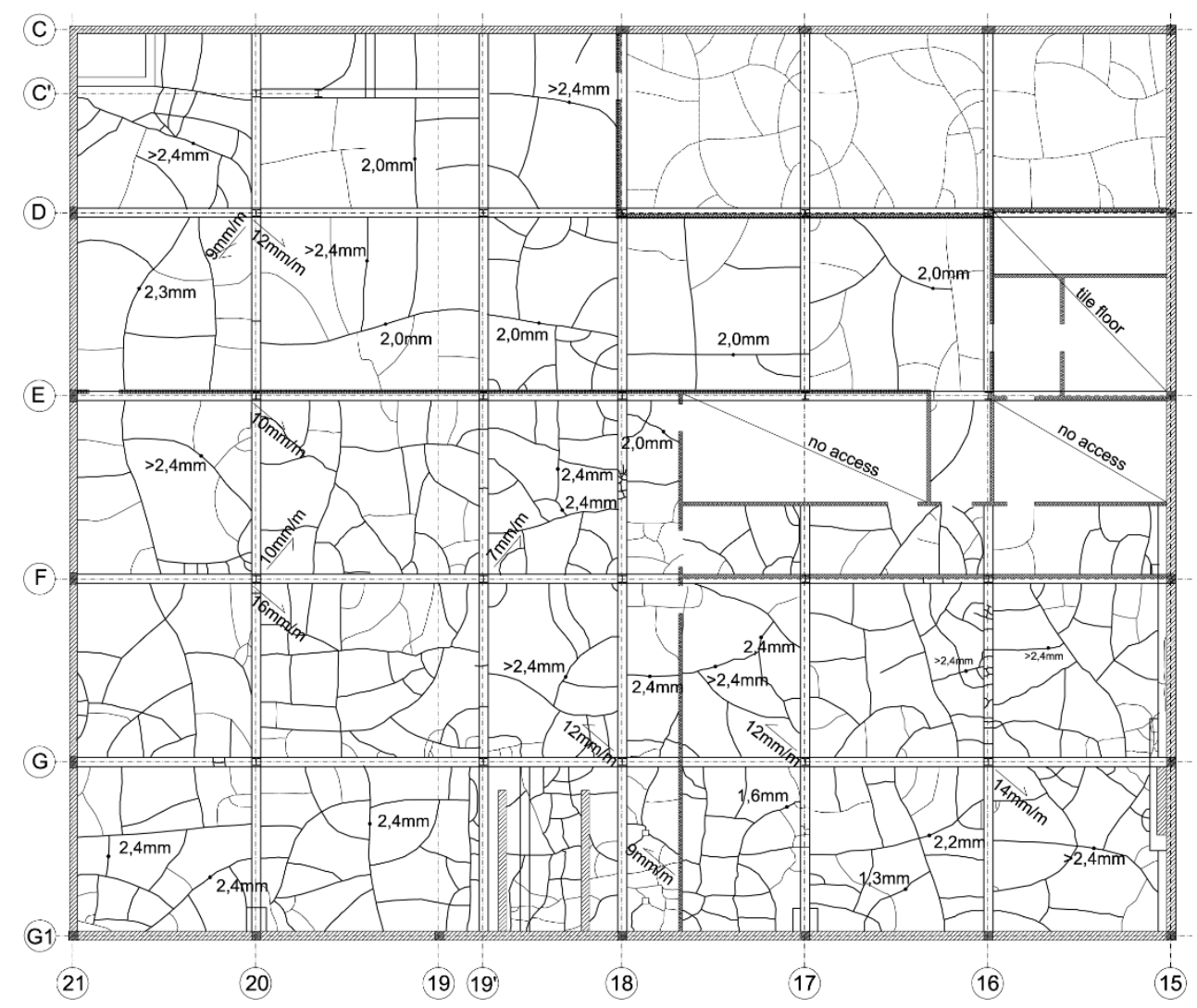

Fig. 3. Floor damage. The values of slopes and crack width are given. 
a)

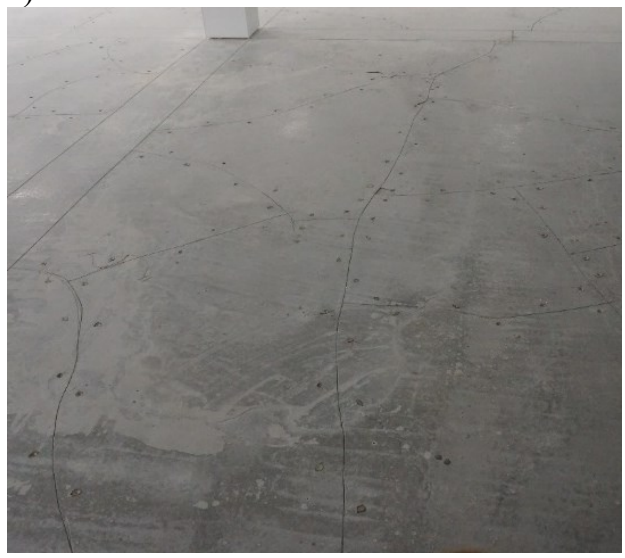

c)

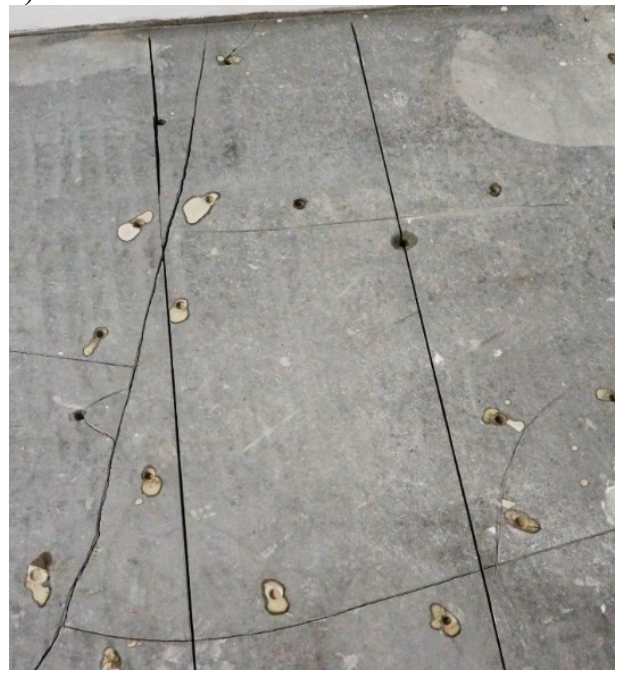

e)

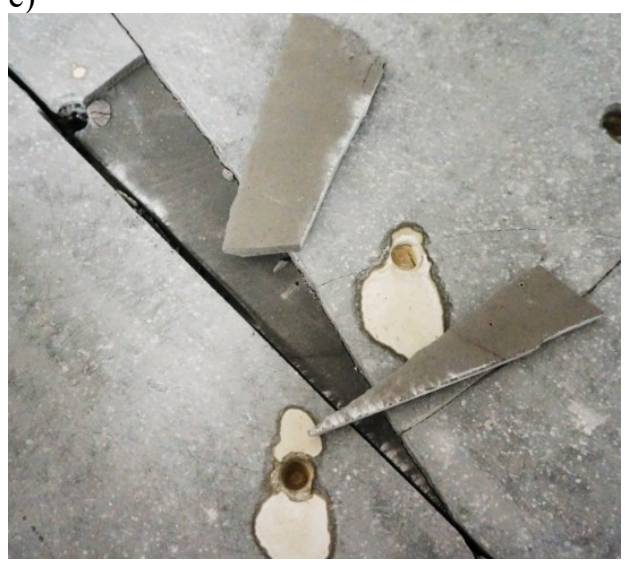

b)

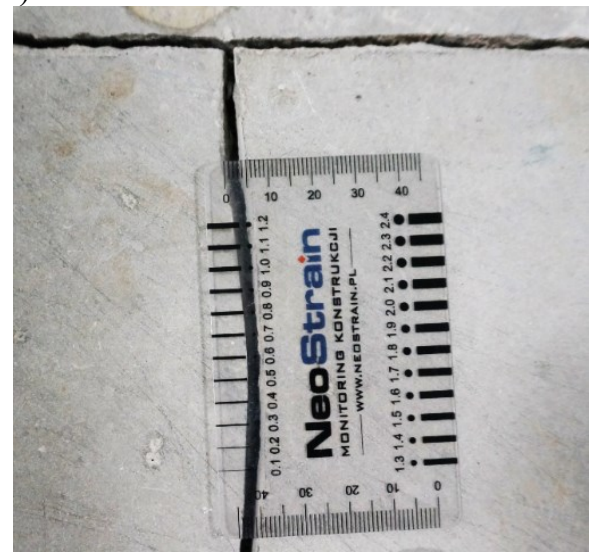

d)

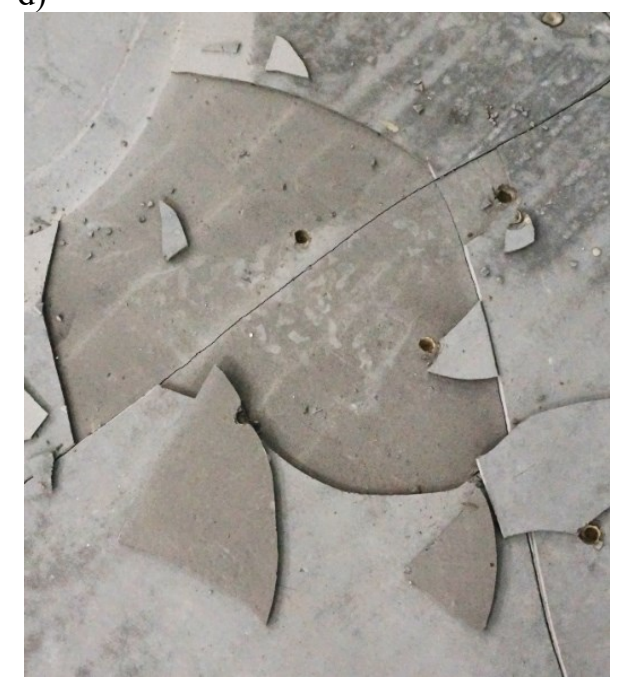

f)

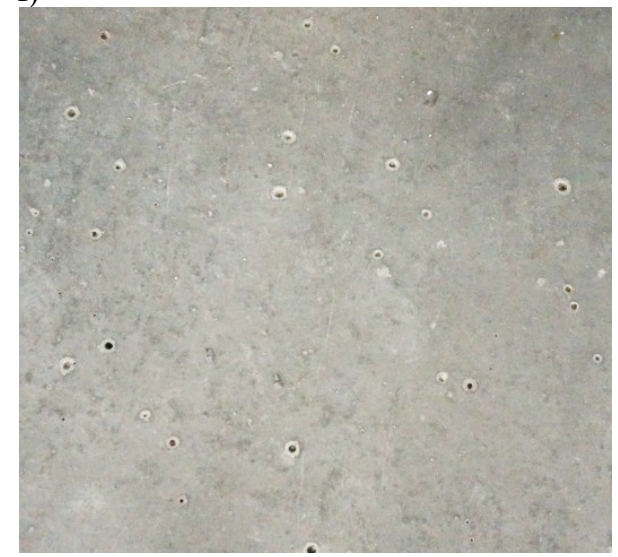

Fig. 4. Damage type: a) cracking, b) crack width measurement, c) cracks protruding through expansion joint, d) e) self-leveling layer detachment, f) pores caused by improper mixing. 
a)

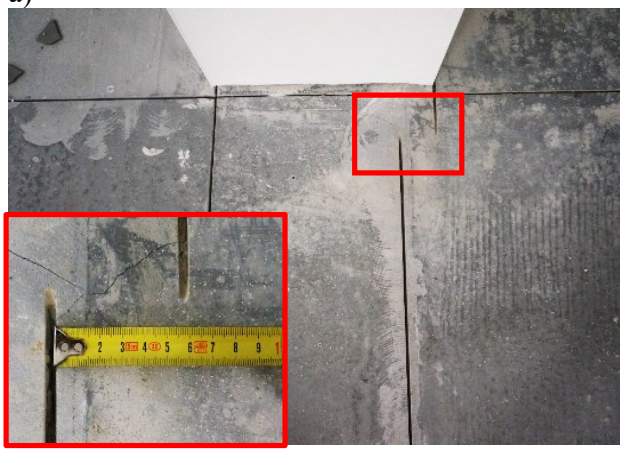

c)

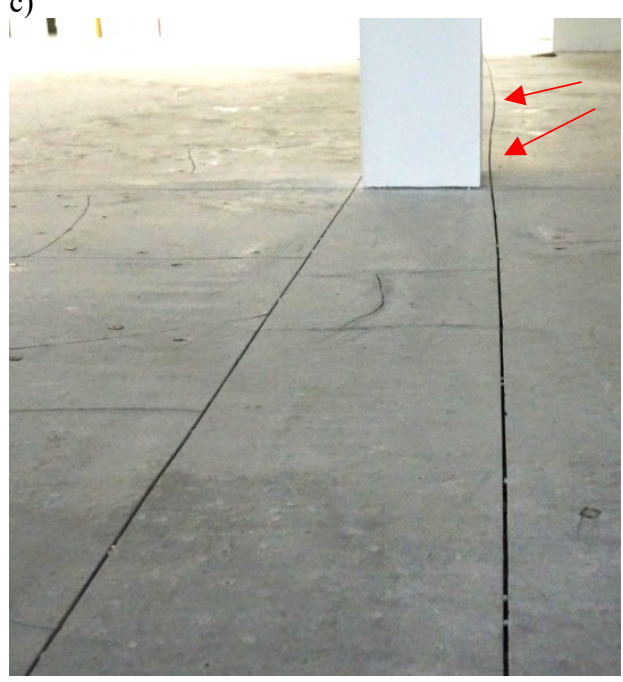

b)

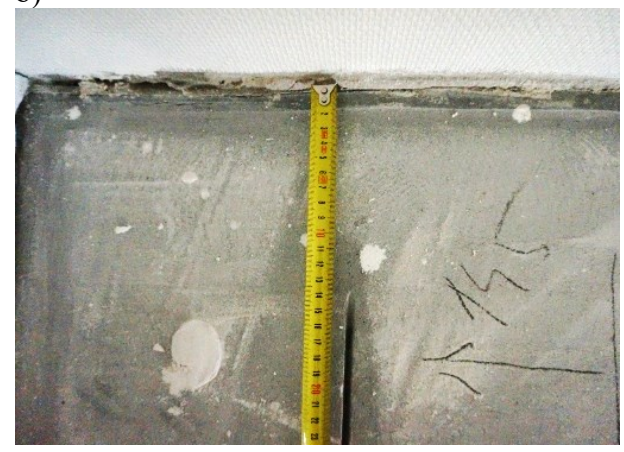

d)

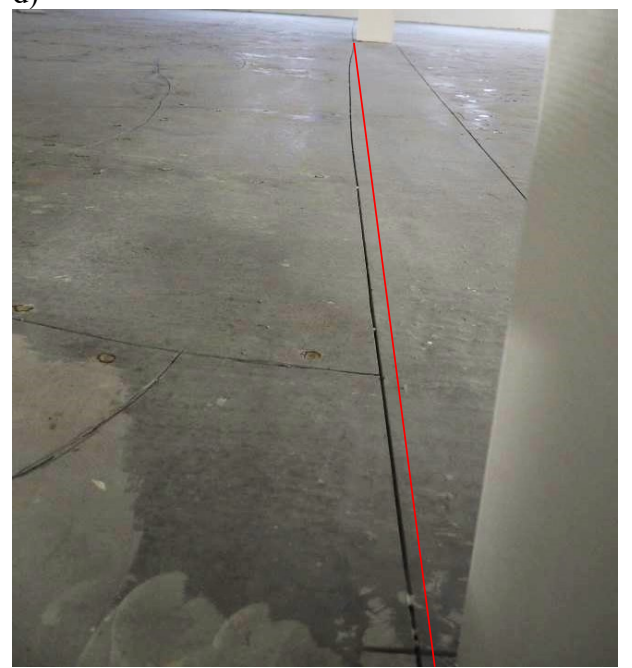

e)

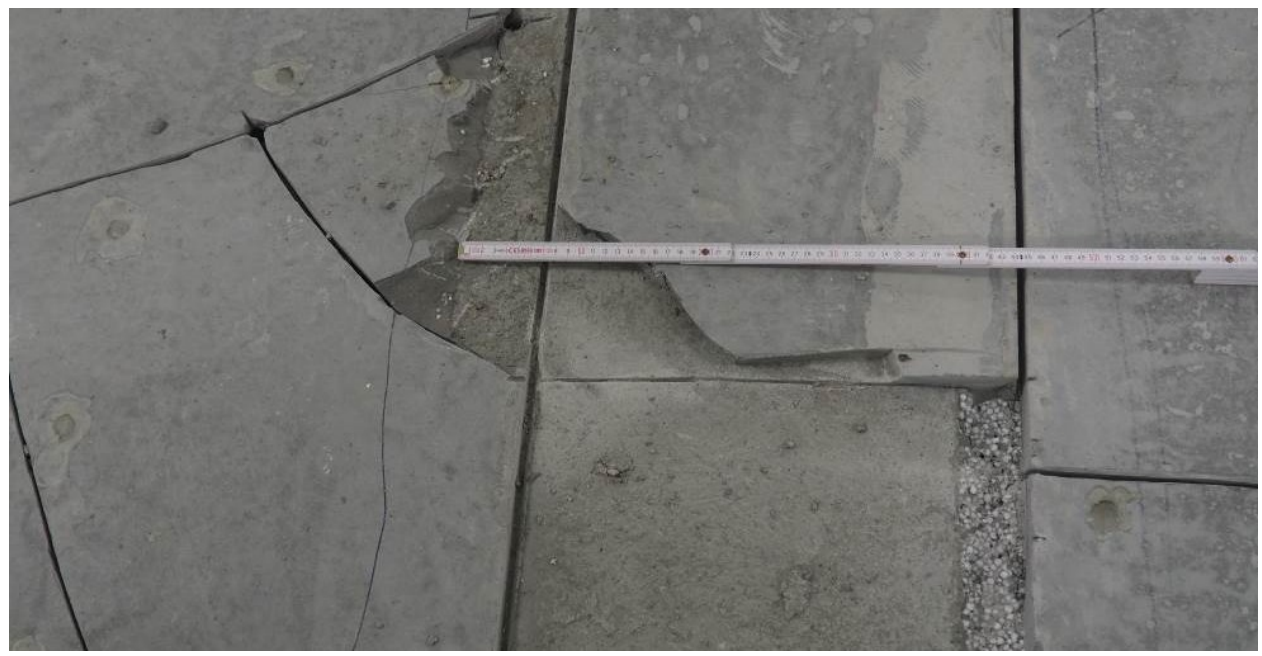

Fig. 5. Imprecise expansion joints: a) lack of continuity, b) improper cut near the wall, c), d) uneven cuts e) inverted beam exposure. Expansion joints are at the distance of $7 \mathrm{~cm}$. 
a)

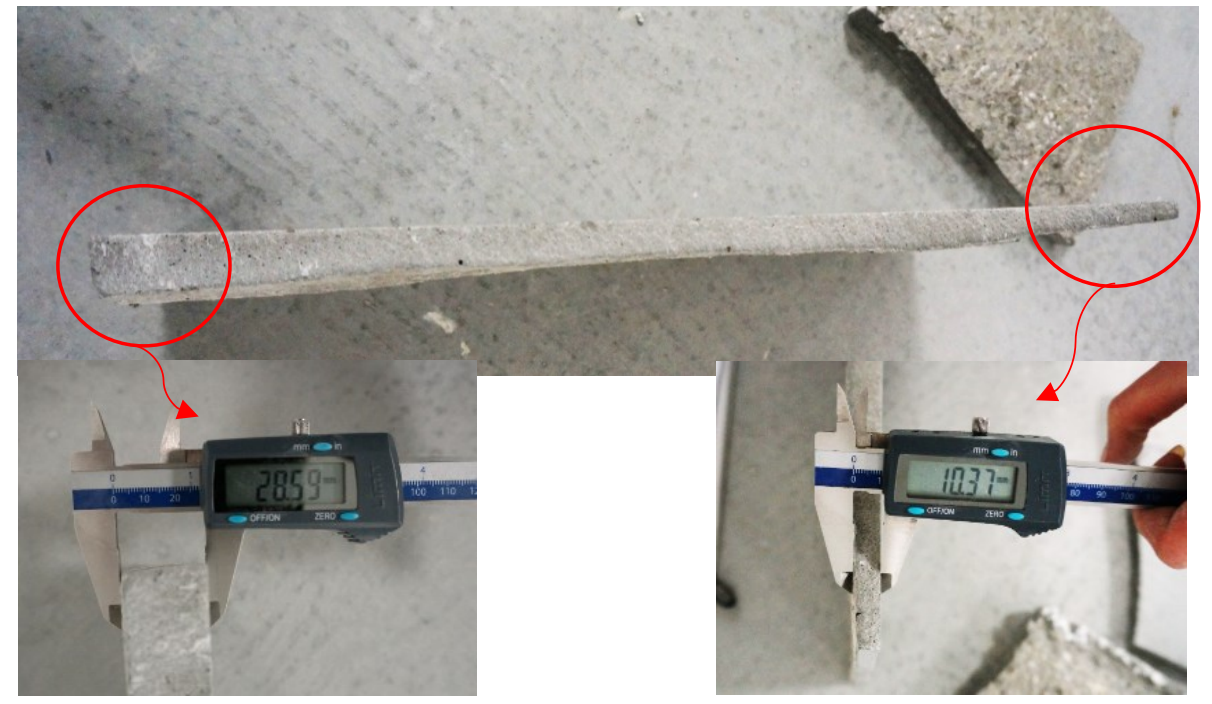

b)

c)
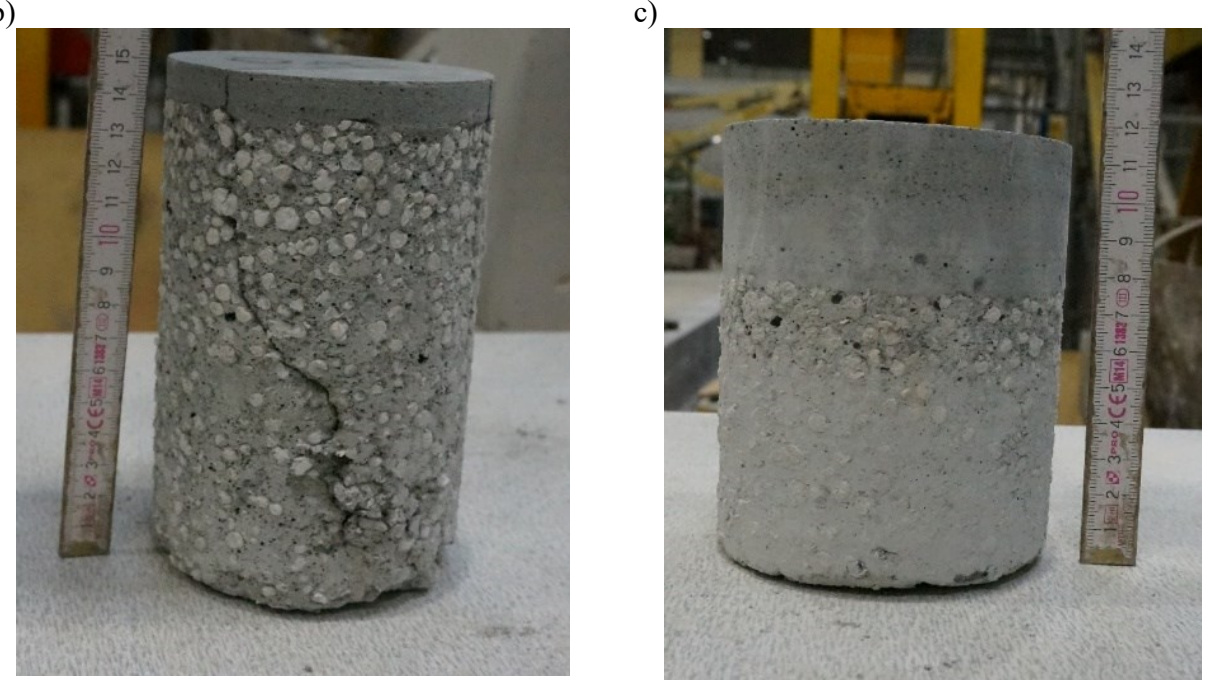

Fig. 6. Changes in thickness of self-leveling screed and EPSC layer: a) measurement of detached screed layer $10.37 \div 28.59 \mathrm{~mm}$, b) EPS concrete layer $(140 \mathrm{~mm})$ in a core sample, $10 \mathrm{~mm}$ of screed, c), EPS concrete layer $(75 \mathrm{~mm})$ in a core sample, $42 \mathrm{~mm}$ of screed.

\section{Laboratory tests}

Several technical assessments commissioned by the contractor stated that pouring a self-leveling screed over a EPS concrete layer is not in line with manufacturers recommendations. The specification recommended casting the self-leveling layer over a seasoned cement or concrete layer. The assessments pointed also on unnecessary use of reinforcement pins in the EPSC layer as well as lack of slip membrane between concrete overlay and EPSC. Comparative tests were carried out in order to demonstrate feasibility of concrete screed over the EPSC layer with pins. Additionally, pull-off tests, strength tests as well as determination of floor flatness and levelness were carried out. 


\subsection{Comparative tests}

In order to determine the possible interaction between individual layers of the floor, four test specimen were prepared. Three of them were made on a $95 \times 295 \mathrm{~cm}$ reinforced concrete slab, the last one on a PVC foil (Fig. 7). The first sample was reinforced with steel $12 \mathrm{~mm}$ pins, with $10 \mathrm{~cm}$ of a 30/50 EPSC overlay and $2 \mathrm{~cm}$ of self-leveling screed. The model reflected the existing floor. Sample no. 2, was identical to the first one with exclusion of reinforcement pins which were not installed. The model, in comparison to the first one, was used to determine the effect of the pins. In sample no. 3, a 30/50 EPSC was cast on a PVC foil and finished with a $2 \mathrm{~cm}$ layer of self-levelling screed. The model was used to determine the possible influence of slip membrane laid under the EPSC. The last sample, a $10 \mathrm{~cm}$ layer of 30/50 EPSC cast over a reinforced concrete slab. was made in order to determine the possible shrinkage. The specimen was left uncured and uncovered, untypically to standard practices. The samples are shown in Fig. 8 and Fig. 9.

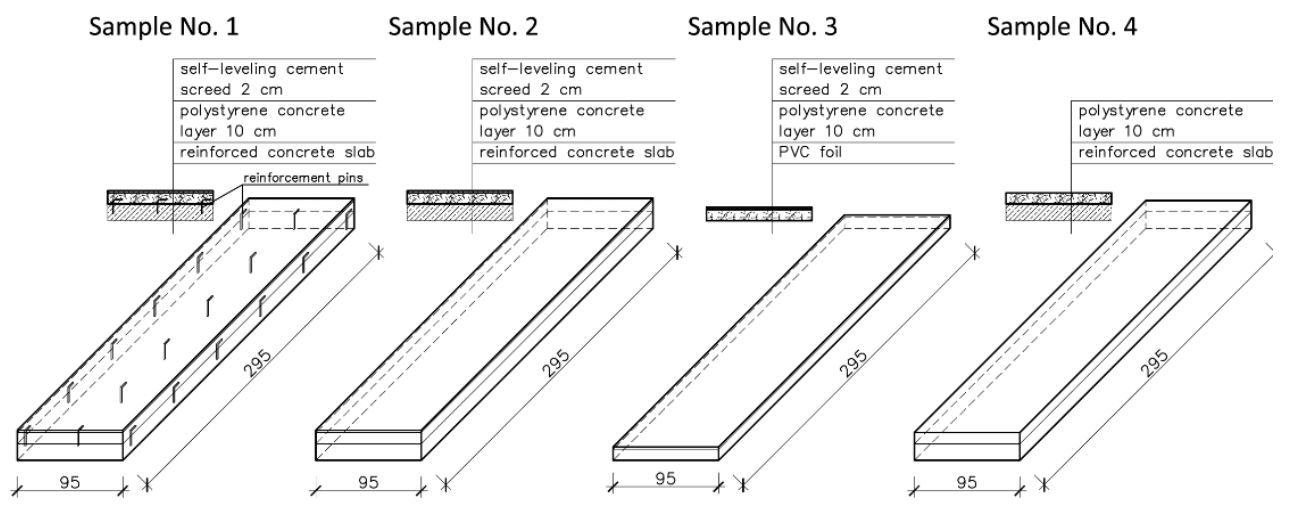

Fig. 7. Comparative test samples.

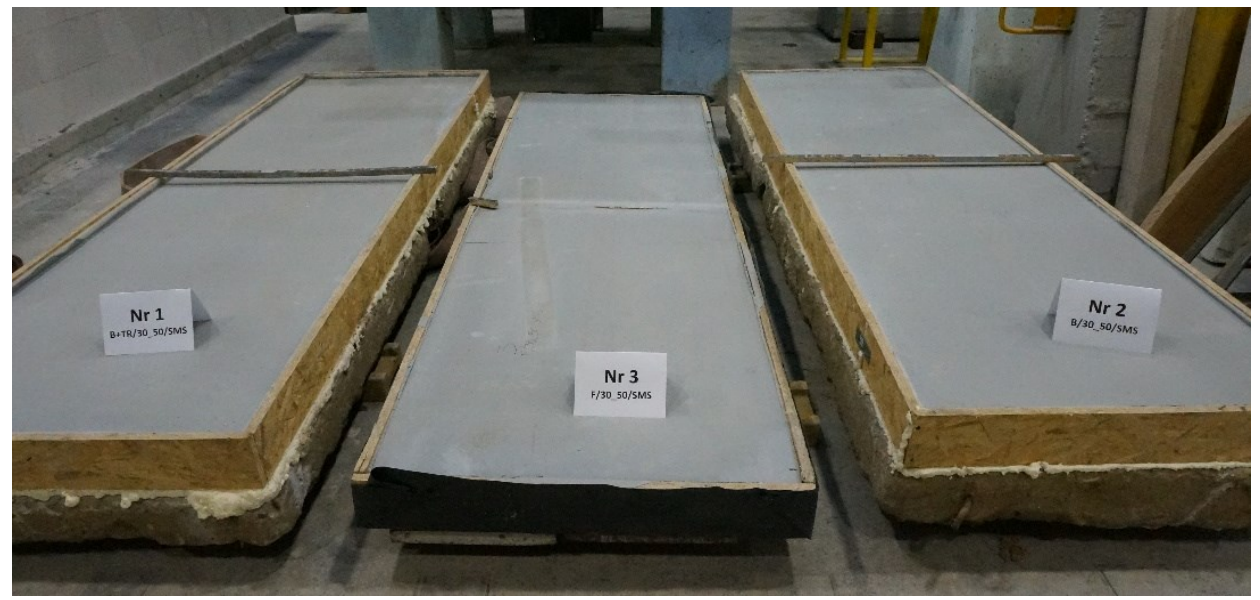

Fig. 8. Samples no. 1, 2 and 3. 


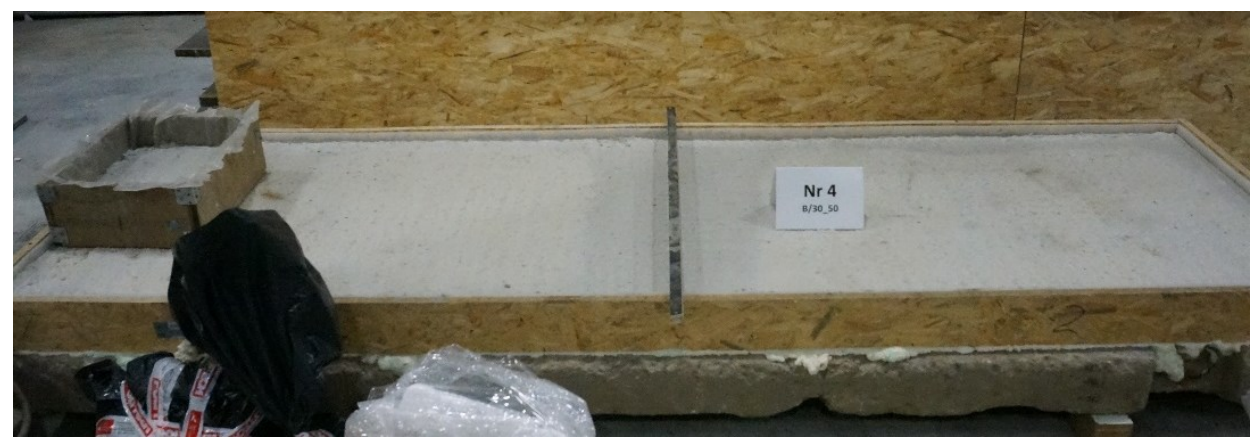

Fig. 9. Sample no. 4.

The visual evaluation of the samples was being conducted for over 2 months. The observations lasted over 2,5 times longer than the time in which the cracks occurred in analyzed floor. After 49 days first three samples did not exhibit any signs of cracking. The last sample exhibited small shrinkage cracks. Local width of the crack reached between $0.1 \div 0.5 \mathrm{~mm}$. The cracks on the surface of the EPSC occurred after two weeks due to lack of curing. The cracks are shown in Fig. 10.

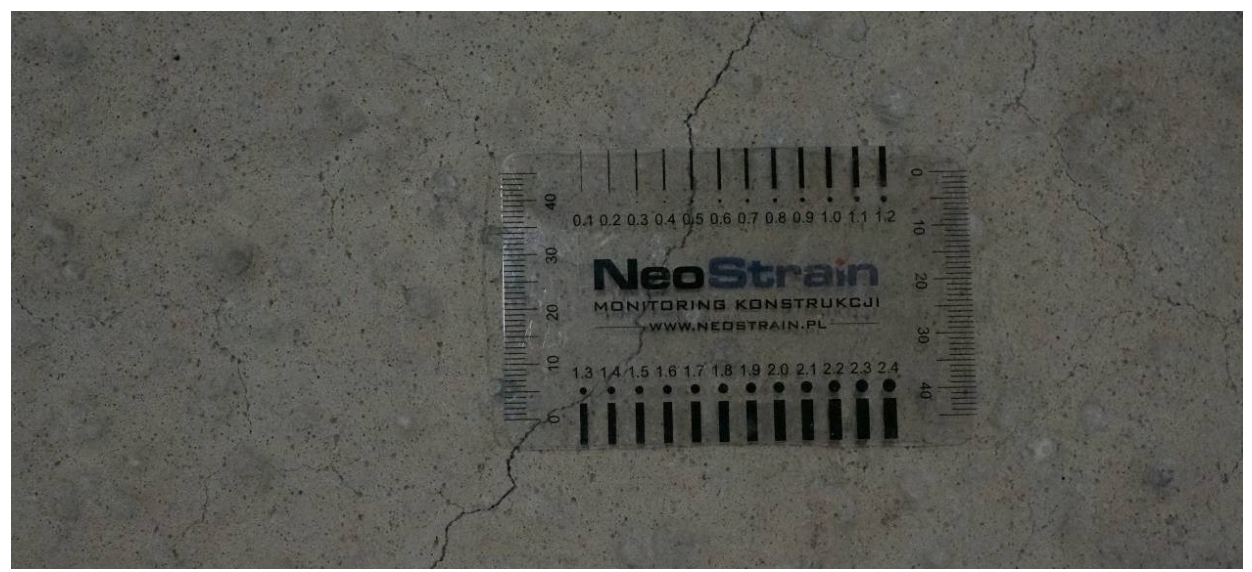

Fig. 10. Measurement of the cracks in sample no. 4 .

Comparative tests have shown that it is possible to make a self-levelling screed for the designed floor. Lack of curing resulted in the occurrence of cracks in the EPS concrete.

\subsection{Pull-off test}

Pull-off tests were carried out both on the actual floor as well as on samples no. 1 and 2. The aim of the test was to determine the adhesion between the screed and EPS concrete base. The tests were carried out in accordance with [8]. The results of pull-off test are given in Table 1. Six measurements were taken for each sample as well as for the actual floor. 
Table 1. Results of the pull-off test for the damaged floor and samples no. 1 and 2.

\begin{tabular}{|c|c|c|c|}
\hline \multicolumn{2}{|c|}{ Sample } & Screed thickness, mm & Stress at break, N/mm² \\
\hline \multirow{6}{*}{$\begin{array}{l}\text { damaged } \\
\text { floor }\end{array}$} & 1 & $13-20$ & 0.28 \\
\hline & 2 & $13-15$ & 0.12 \\
\hline & 3 & $12-15$ & 0.21 \\
\hline & 4 & 35 & 0.34 \\
\hline & 5 & 40 & 0.19 \\
\hline & 6 & 40 & 0.26 \\
\hline \multirow{6}{*}{ No 1} & 1 & 21 & 0.26 \\
\hline & 2 & 20 & 0.21 \\
\hline & 3 & 21 & 0.26 \\
\hline & 4 & 21 & 0.26 \\
\hline & 5 & 20 & 0.23 \\
\hline & 6 & 20 & 0.22 \\
\hline \multirow{6}{*}{ No 2} & 1 & 21 & 0.21 \\
\hline & 2 & 22 & 0.26 \\
\hline & 3 & 21 & 0.26 \\
\hline & 4 & 20 & 0.23 \\
\hline & 5 & 21 & 0.26 \\
\hline & 6 & 21 & 0.23 \\
\hline
\end{tabular}

The pull-off tests conducted on the damaged floor resulted in the stress at break between $0.12 \div 0.34 \mathrm{~N} / \mathrm{mm}^{2}$. The test concurred previous observation of uneven thickness of the floor screed. The thickness of the screed was between 12 and $40 \mathrm{~mm}$, only in P1 measurement point obtaining desired value. The samples before and after the pull-off test are shown in Fig. 11.

In the performance declaration, the manufacturer declares layer-to-layer adhesion of at least $0.2 \mathrm{~N} / \mathrm{mm}^{2}$. As seen from the results, the local adhesion did not meet the requirements.

a)

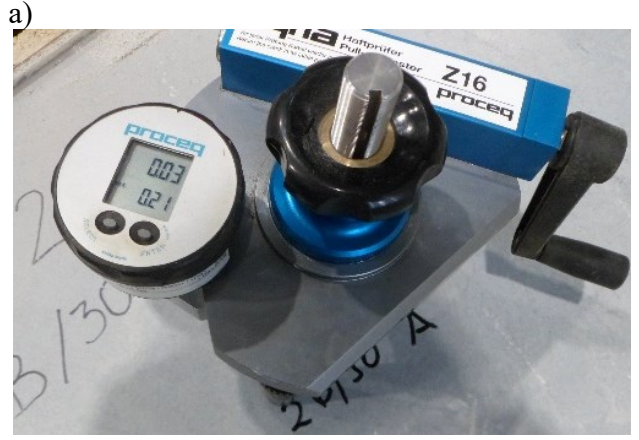

b)

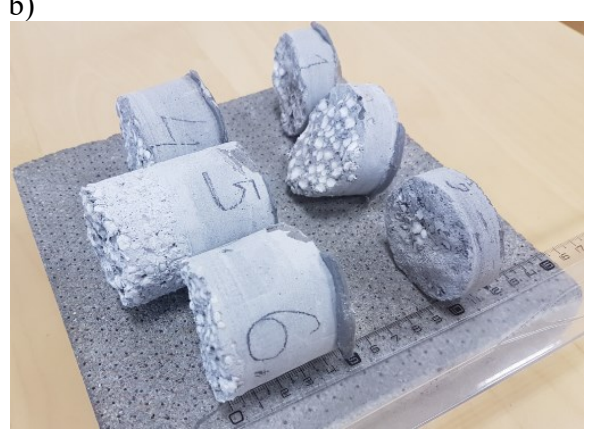

Fig. 11. Sample (no. 2) during the test and afterwards (samples from the damaged floor).

Both prepared laboratory specimen, unlike the samples taken from damaged floor exhibited higher stress at break, than $0,2 \mathrm{~N} / \mathrm{mm}^{2}$ declared by the manufacturer. The test results were homogenous, with $\mathrm{SD}=0.02$ and $\mathrm{CoV}=8,7 \%$ for samples no. 1 and 2 . 


\subsection{Strength tests}

Following tests were performed: compressive strength of the EPSC, tensile strength on cylindrical samples (EPSC + screed), flexural and compressive strength of the screed and determination of screed density. Tests were performed on samples taken from the damaged floor as well as from specimen no. 1-3. Results of conducted tests are shown in Tables 2-4.

Table 2. Density and compressive strength of samples.

\begin{tabular}{|c|c|c|c|c|c|c|c|}
\hline \multicolumn{2}{|c|}{ Sample } & $\begin{array}{c}\text { Height } \\
\text { m }\end{array}$ & $\begin{array}{c}\text { Area } \\
\mathbf{m}^{2}\end{array}$ & $\begin{array}{c}\text { Volume } \\
\mathbf{m}^{3}\end{array}$ & $\begin{array}{c}\text { Mass } \\
\text { kg }\end{array}$ & $\begin{array}{l}\text { Density } \\
\mathrm{kg} / \mathrm{m}^{3}\end{array}$ & $\begin{array}{c}\text { Comp. strength } \\
\mathrm{N} / \mathrm{mm}^{2}\end{array}$ \\
\hline \multirow{3}{*}{$\begin{array}{l}\text { damaged } \\
\text { floor }\end{array}$} & 1 & 0.101 & 0.0069 & 0.000701 & 0.358 & 510.76 & 2.074 \\
\hline & 2 & 0.101 & 0.0069 & 0.000701 & 0.319 & 455.12 & 1.924 \\
\hline & 3 & 0.101 & 0.0069 & 0.000701 & 0.278 & 396.62 & 1.365 \\
\hline \multirow{3}{*}{$\mathrm{nr} 1$} & 1 & 0.075 & 0.00694 & 0.00052 & 0.186 & 357.36 & 1.210 \\
\hline & 2 & 0.071 & 0.00694 & 0.000493 & 0.209 & 424.17 & 1.246 \\
\hline & 3 & 0.065 & 0.00694 & 0.000451 & 0.214 & 474.41 & 1.321 \\
\hline \multirow{3}{*}{ nr 2} & 1 & 0.084 & 0.00694 & 0.000583 & 0.246 & 422.00 & 1.199 \\
\hline & 2 & 0.083 & 0.00694 & 0.000576 & 0.235 & 407.98 & 1.215 \\
\hline & 3 & 0.082 & 0.00694 & 0.000569 & 0.253 & 444.59 & 1.282 \\
\hline \multirow{3}{*}{$\mathrm{nr} 4$} & 1 & 0.097 & 0.00694 & 0.000673 & 0.273 & 405.55 & 1.300 \\
\hline & 2 & 0.095 & 0.00694 & 0.000659 & 0.286 & 433.81 & 1.317 \\
\hline & 3 & 0.091 & 0.00694 & 0.000632 & 0.277 & 438.62 & 1.213 \\
\hline
\end{tabular}

Table 3. Results of tensile strength tests of the EPSC+screed samples.

\begin{tabular}{|c|c|c|c|c|c|}
\hline \multicolumn{2}{|c|}{ Sample } & $\begin{array}{c}\text { Diameter, } \\
\mathbf{m}\end{array}$ & $\begin{array}{c}\text { Area, } \\
\mathbf{m}^{2}\end{array}$ & $\begin{array}{c}\text { Force, } \\
\mathbf{k N}\end{array}$ & $\begin{array}{c}\text { Tensile strength, } \\
\mathbf{N} / \mathbf{m m}^{2}\end{array}$ \\
\hline \multirow{3}{*}{$\begin{array}{l}\text { damaged } \\
\text { floor }\end{array}$} & 1 & 0.094 & 0.00694 & 1.20 & 0.17 \\
\hline & 2 & 0.094 & 0.00694 & 1.12 & 0.16 \\
\hline & 3 & 0.094 & 0.00694 & 0.16 & 0.02 \\
\hline \multirow[b]{2}{*}{ nr 1} & 1 & 0.094 & 0.00694 & 0.78 & 0.112 \\
\hline & 2 & 0.094 & 0.00694 & 0.84 & 0.121 \\
\hline \multirow{2}{*}{$\mathrm{nr} 2$} & 1 & 0.094 & 0.00694 & 0.80 & 0.115 \\
\hline & 2 & 0.094 & 0.00694 & 0.81 & 0.117 \\
\hline
\end{tabular}

Table 4. Flexural strength test results of the screed samples.

\begin{tabular}{|c|c|c|c|c|c|c|}
\hline \multicolumn{2}{|c|}{ Sample } & $\begin{array}{c}\text { Height in the } \\
\text { middle, } \mathbf{m m}\end{array}$ & $\begin{array}{c}\text { Width, } \\
\text { mm }\end{array}$ & $\begin{array}{c}\text { Supports } \\
\text { spacing, mm }\end{array}$ & $\begin{array}{c}\text { Force, } \\
\text { N }\end{array}$ & $\begin{array}{c}\text { Flexural strength, } \\
\text { N/mm }\end{array}$ \\
\hline \multirow{3}{*}{$\begin{array}{c}\text { damaged } \\
\text { floor }\end{array}$} & 1 & 26 & 40 & 100 & 1507 & 8.36 \\
\cline { 2 - 7 } & 2 & 40 & 40 & 100 & 3300 & 7.73 \\
\cline { 2 - 7 } & 3 & 21 & 40 & 110 & 641 & 6.00 \\
\hline \multirow{4}{*}{ nr 1 } & 4 & 25 & 40 & 110 & 1220 & 8.05 \\
\cline { 2 - 7 } & 1 & 17 & 40 & 110 & 598 & 8.54 \\
\cline { 2 - 7 } & 2 & 17 & 40 & 110 & 497 & 7.09 \\
\cline { 2 - 7 } & 4 & 15 & 40 & 110 & 429 & 7.87 \\
\hline \multirow{4}{*}{ nr 2 } & 1 & 15 & 40 & 110 & 409 & 7.50 \\
\cline { 2 - 7 } & 2 & 16 & 40 & 110 & 532 & 8.57 \\
\cline { 2 - 7 } & 3 & 15 & 40 & 110 & 478 & 8.76 \\
\cline { 2 - 7 } & 4 & 18 & 40 & 110 & 595 & 7.58 \\
\hline \multirow{4}{*}{ nr 3 } & 1 & 20 & 40 & 110 & 696 & 7.95 \\
\cline { 2 - 7 } & 2 & 19 & 40 & 110 & 692 & 7.14 \\
\cline { 2 - 7 } & 3 & 18 & 40 & 110 & 632 & 7.22 \\
\cline { 2 - 7 } & 4 & 19 & 40 & 110 & 590 & 7.51 \\
\hline
\end{tabular}

Conducted tests have determined that the materials used (p. 4.1) in the comparative laboratory tests meet the manufacturers recommendations in terms of compressive and flexural strength. Core samples from the damaged floor in majority also exhibited required 
compressive and tensile strength. A single sample exhibited significantly lower flexural strength, while the other did not meet the tensile strength requirements.

a)

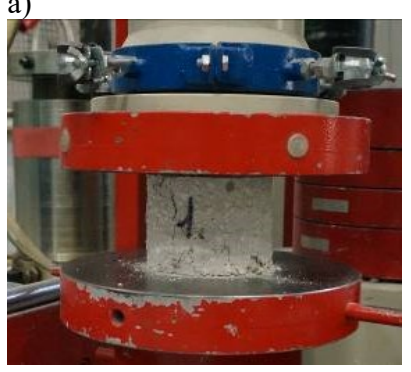

b)

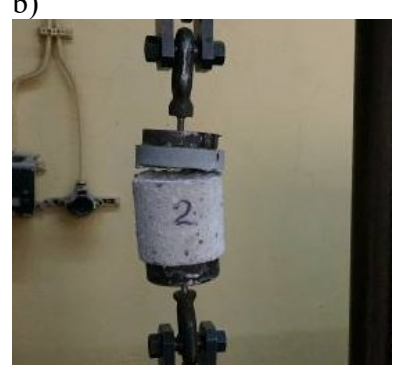

c)

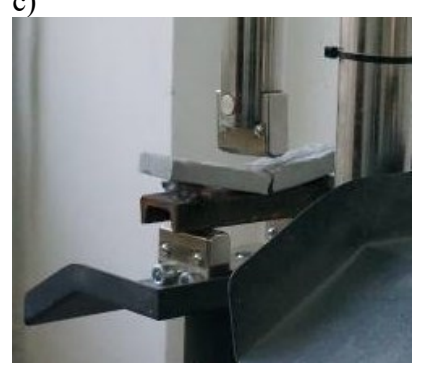

Fig. 12. Laboratory tests: a) compressive strength test of the EPS concrete, b) tensile strength test of the EPSC + screed samples, c) flexural strength test of the screed.

\subsection{Screed flatness and levelness determination}

Except of a simple determination of the flatness with a two-meter-long level the levelness was also determined using a laser scanner. Measuring points were spread over a $50 \mathrm{~cm}$ grid. Due to existing partition walls the floor was divided into 5 separate areas. The differences between the highest and lowest measured points in those areas was in order: $19.86 \mathrm{~mm}$, $11.43 \mathrm{~mm}, 10.78 \mathrm{~mm}, 20.66 \mathrm{~mm}$ and $11.61 \mathrm{~mm}$.

\section{Cause of damages}

The cracking of the industrial floors can occur due to excessive load, improper material interaction or, like in the case of analyzed floor, performance errors. The errors included: uneven thickness of the screed, late preparation of expansion joints and uneven cuts, and performing works under higher than recommended temperatures. Condition assessment also showed uneven thickness of the self-leveling screed, stratification of the layers and improper mixing of the screed components. Those numerous performance errors resulted in cracking, stratification, lack of flatness and uneven surface. Each additional tie added to a freely deforming system generates internal forces. In this particular case the unevenness in the interaction zone between EPSC and screed and lack of homogeneity in both materials generated additional stresses.

\section{Repair}

An attempt was made to repair damaged floor in a selected field of $4.7 \times 6.0 \mathrm{~m}$. It was decided to perform repair by stitching cracks with a thin copper stainless steel wire, perpendicular to their course, filling possible empty spaces with cement-based mortar. Stitching reinforcement was placed in incisions every $20 \div 25 \mathrm{~cm}$. The places of stitching and cracks were filled with an injection resin (Fig. 13). This method allowed for a tight connection of floor fragments separated by cracks. It also allowed to obtain a smooth surface under the planned top floor, which was the base for the final finishing of carpet floors. Since the sample repair has proved correct, the whole floor was repaired with this method. 
a)

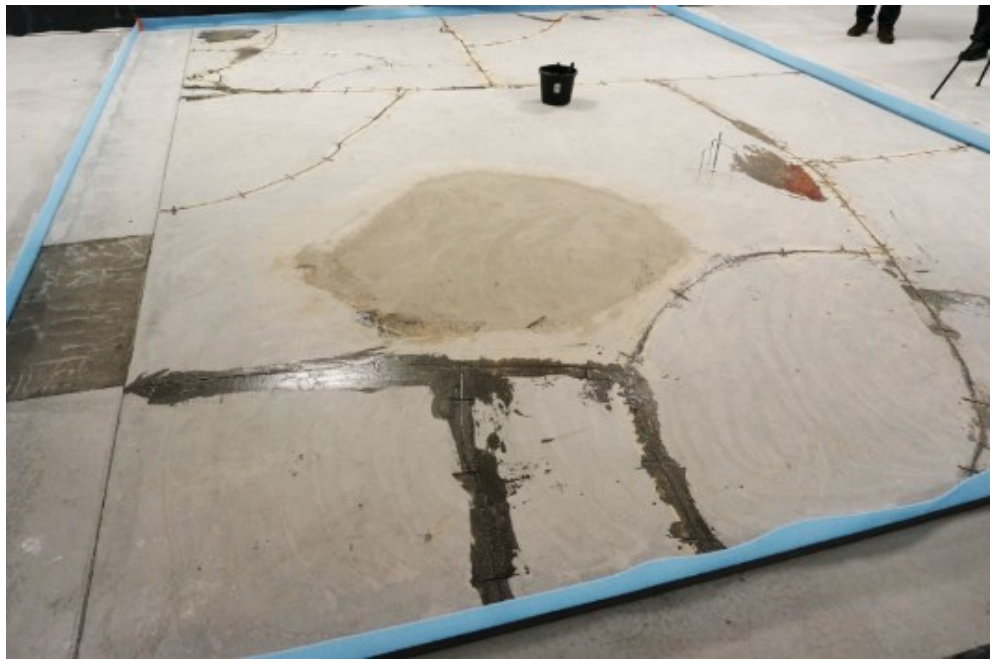

b)

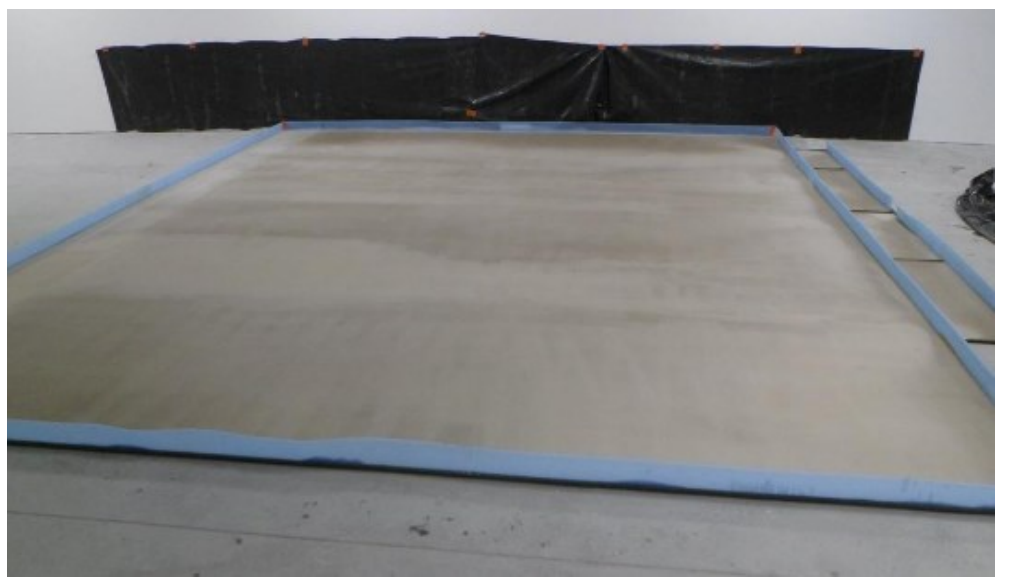

Fig. 13. Repair method: a) view after stitching and injection of the cracks, b) finished top layer.

\section{References}

1. J. Bolden, T. Abu-Lebdeh, E. Fini, Amer. J. Environ. Sci. 9, pp. 14-24, (2013)

2. C.A. Cadere, M. Barbuta, B. Rosca, A.A. Serbanoiu, A. Burlacu, I. Oancea, Procedia Manufact. 22, pp. 288-293 (2018)

3. N. Tsvetkov, A. Khutornoi, A. Kozlobrodov, S. Romanenko, Y. Shefer, A. Golovko, MATEC Web of Conf. 143, pp. 01005 (2018)

4. M. Wesołowska, P. Szczepaniak, J. Gajewski, IOP Conf. Ser.: Mat. Sci. Eng. 415, pp. 1-8 (2018)

5. R. Demirboga, K. Abdulkadir, Constr. Build. Mater. 35, pp. 730-734 (2012)

6. W. C. Tang, H. Z. Cui, M. Wu, Constr. Build. Mater. 51, pp. 338-343 (2014)

7. Y. Xu, L. Jiang, J. Xu, Y. Li, Constr. Build. Mater. 27, pp. 32-38 (2012)

8. Ł. Drobiec, R. Jasiński, A. Piekarczyk, Diagnostic testing of reinforced concrete structures. Methodology, field tests, laboratory tests of concrete and steel (Scientific Company PWN, Warsaw, 2010) [in Polish] 